\title{
An empirical formula to estimate rainfall intensity in Kupwara region of Kashmir valley, $\mathrm{J}$ and $\mathrm{K}$, India
}

\author{
Abdul Qayoom Dar ${ }^{1 a}$, Humairah Maqbool ${ }^{1}$, Syeedah Raazia ${ }^{1}$ \\ ${ }^{1}$ Department of Civil Engineering, National Institute of Technology, Srinagar, J\&K, India
}

\begin{abstract}
Knowledge of rainfall extremes particularly their magnitude and frequency, as embodied in Intensity-DurationFrequency (IDF) relationships and IDF curves is fundamental to many engineering problems such as design of hydraulic structures, urban drainage system, water resources projects and many others. The objective of this study is to obtain IDF relationships and curves for the Kupwara region of Kashmir valley in Jammu and Kashmir, India. Three different frequency distributions namely the Gumbel distribution, the Pearson Type III distribution and the Log-Pearson Type III distribution were fitted to the rainfall data to obtain rainfall intensities for selected return periods $(2,5,10,25,50$ and 100 years) and durations $(0.16,0.5,1,3,6,12$ and 24 hours). Regional constants in IDF relations were found using the Sherman Morrison method and results were compared based on the Chi-square goodness-of-fit test. Results obtained using all distributions showed a similar trend. However, the Pearson Type III distribution emerges to be the best fit for the rainfall data of the region. Results revealed that higher rainfall intensities have shorter durations. Maximum rainfall intensity $81.13 \mathrm{~mm} / \mathrm{hr}$ as per the best fit relation occurs with a return period of 100 years for 0.16 hours duration.
\end{abstract}

\section{Introduction}

Assessment of extreme precipitation is an important problem in hydrologic risk analysis and design. Knowledge of extreme events with respect to their frequency (exceedance probability) and magnitude is important towards planning for weather-related emergencies, design of engineering structures, reservoir management, etc. Evaluation of rainfall extremes has thus been a major focus of both theoretical and applied hydrology. A popular means of quantifying rainfall extremes or their frequency is through the Intensity-Duration-Frequency (IDF) relationships. IDF relationships are empirical relationships between the intensity of rainfall, duration of rainfall and the return period (inverse of the exceedance probability). IDF curves are three parameter curve in which duration of precipitation is taken as abscissa, intensity of precipitation as the ordinates and the return period or frequency as the third parameter.

IDF curves provide for the estimation of the return period of a given rainfall event or the amount of rainfall corresponding to a given return period. IDF curves find applications in the design of hydraulic structures (such as culverts and bridges), roads and urban drainage systems, land-use planning and soil conservation studies, management of municipal infrastructure including sewers, storm water management, ponds and street curb, design of safe and economical structures for the control, storage and routing of storm water and surface drainage and risk assessment of dams and bridges. The curves can also be used as input to rainfall-runoff models that simulate floods for bridge and spillway design. IDF relationships are used in the rational method of peak runoff estimation to determine the average rainfall intensity for a selected time of concentration. IDF curves are also useful in analysing the effects of climate change on precipitation parameters.

Many researchers in the past have developed IDF curves for different regions of the world. Bell, 1969[1] developed IDF curves for certain areas of U.S.S.R; Al-Sheikh, 1985[2] derived IDF relations for Saudi Arabia. Al-Khalaf, 1997[3] conducted a study for predicting short-duration, high intensity rainfall in Saudi Arabia using IDF studies. Koutsoyiannis (1998)[4] proposed construction of the intensity-duration-frequency curves using data from both recording and non-recording stations. Elsebaie, 2012 [5] developed IDF relationship for two regions in Saudi Arabia. Ogarekpe, 2014[6] developed IDF relationships for Calabar Metropolis, South-Nigeria.

Al-Khalaf, 1997[3] suggested that IDF relationships are region specific and should hence be obtained for each region separately. Development of IDF relationships largely involves the knowledge of the underlying distribution. Commonly used distributions in IDF and other similar other studies include Gumbel, Generalised Extreme

\footnotetext{
a Corresponding author: aqdar_nitsri@rediffmail.com
} 
Value, Pearson Type III and Log Pearson Type III distributions (Al-Dokhayel, 1986[7]; Dupont and Allen, 2000[8]; Hadadin, 2005[9]; Nhat et al., 2006[10] and AlHassoun, 2011 [11]). The present study focuses on the development of IDF curves and hence IDF relationships for Kupwara region of the Kashmir valley using the Gumbel, the Pearson and the Log Pearson distributions.

\section{Study area}

District Kupwara with its head quarters at Kupwara lies in the northern most part of Kashmir valley in the state of Jammu and Kashmir. It is located between $34^{\circ} 16^{\prime}$ and $34^{0} 50^{\prime}$ North Latitudes and $73^{\circ} 45^{\prime}$ and $75^{\circ} 20^{\prime}$ East Longitudes, $82 \mathrm{~km}$ from the state capital, Srinagar. The district has a geographical area of 2379 square kilometers. The average height of the district is 1,581 metres above sea level. The district is flanked in the east and south by district Baramulla and in the west and north by the Line of Control. The region has a varied topography with the western, northern and eastern areas of the district being hilly while as the southern areas being mainly plain. The major physiographic features of the region include high karewa plateau lands, sharp ridges of hard rock and intervening valleys. Most of the land is covered either with forests or under agriculture. The region is largely drained by the Kishan Ganga River. Average minimum and maximum temperatures vary from $-5^{\circ} \mathrm{C}$ to $32^{\circ} \mathrm{C}$, with the higher reaches remaining cold throughout the year. The average annual rainfall in this region is $869 \mathrm{~mm}$.

\section{Methodology}

\subsection{Data collection and processing}

There are in all six rain gauge stations in Kashmir valley, located at Srinagar, Pahalgam, Kupwara, Gulmarg, Kokernag and Qazigund. In the present study, rainfall data from Kupwara rain gauge station has been selected for determination of Intensity-duration-frequency relationships of the region.

Rainfall data corresponding to the period from 1978 to 2004 (30 years) for Kupwara region was procured from Indian Meteorological Department Srinagar Kashmir (IMD). From the raw data, maximum rainfall events for selected durations (10 minutes, 30 minutes, 1 hour, 2 hours, 3 hours, 6 hours, 12 hours and 24 hours) were sorted for each year. Then, mean and standard deviations were calculated for each of the annual maximum series of different durations.

\subsection{Development of IDF curves}

Three probability distributions namely the Gumbel distribution, the Pearson Type III distribution and the Log
Pearson Type III distribution were fitted to each of the annual maximum series of the given durations.

The general statistical equation for rainfall amounts is given by Equation (1). (Chow, 1988 [12])

$$
X_{T}=M+K_{T} s
$$

In the above equation, $\mathrm{X}_{\mathrm{T}}$ is the rainfall amount having return period of $\mathrm{T}$ years, $\mathrm{M}$ is the arithmetic mean of the series, $\mathrm{K}_{\mathrm{T}}$ is known as the frequency factor and depends on the distribution of the series and $\mathrm{s}$ is the standard deviation of the series. The frequency factor multiplied by the standard deviation gives the departure of a certain rainfall value of given return period from the average rainfall. The corresponding rainfall intensity of a given duration rainfall and return period $\mathrm{T}$ years is calculated by Equation (2) as

$$
l=\frac{X_{T}}{T}
$$

\subsubsection{Gumbel distribution}

The Gumbel distribution is the most widely used distribution in the field of hydrology. This distribution is suitable for modeling of maxima. This is a single parameter distribution with frequency factor as the only parameter to be determined. Equation (3) is used to calculate the Gumbel frequency factor.

$$
K_{T}=-\frac{\sqrt{6}}{\pi}\left[0.5772+\ln \left(\ln \frac{T}{T-1}\right)\right]
$$

In Gumbel distribution, the frequency factor is a function of the return period only.

\subsubsection{Pearson Type III distribution}

PT III distribution is normally suitable for skewed data. For this distribution, the frequency factor besides depending on the return period, is also a function of the coefficient of skewness of the data which is obtained by Equation (4) suggested by Chow, 1988 [12] and Burke \& Burke, 2008 [13].

$$
C_{s}=\frac{N \sum_{i=1}^{N}\left(X_{\mathrm{i}}-M\right)^{3}}{(N-1)(N-2) s^{3}}
$$

Frequency factor for each return period and the coefficient of skewness computed using the above equation are then determined using standard tables provided by Water Resources Council, 1967 [14].

\subsubsection{Log Pearson Type-III Distribution}

The LPT III distribution involves the log transformed series of the rainfall data. Using this distribution, the mean, the standard deviation and the skewness coefficient are calculated based on the logarithms of the original data values to the base 10. Frequency factors for all the annual 
maximum series corresponding to different durations are obtained from the available statistical tables as functions of return periods and skewness coefficients. Antilog of the solution obtained from the general statistical equation (Equation 5) provides the estimate for the extreme rainfall for a given duration and return period.

\subsection{Development of IDF equations}

IDF equations are the empirical equations relating the dependent parameter rainfall intensity to the independent parameters return period and duration of rainfall. The general form of an IDF equation is as expressed by Equation (5).

$$
I=\frac{C T^{m}}{T_{d}{ }^{e}}
$$

where $\mathrm{I}$ is the rainfall intensity in $\mathrm{mm} / \mathrm{hr}$; $\mathrm{T}$ is the return period in years and $T_{d}$ is the duration of rainfall in days. $C$, $\mathrm{m}$ and e are known as the regional constants.

Three separate IDF equations were developed for the study area using the data generated by employing the three different distributions mentioned in the previous sections. The IDF equations are linearised using the logarithmic transform. The regional constants in each case were determined by Sherman-Morrison method of solving linear equations. The Chi-square goodness-of-fit test was used to determine the best fit IDF equation.

\section{Results and discussions}

\subsection{IDF curves}

The IDF curves obtained by fitting the Gumbel, the Pearson and the Log-Pearson distributions to rainfall data are respectively given in Figures 1 to3. The Gumbel distribution gives a maximum intensity of $64.42 \mathrm{~mm} / \mathrm{hr}$ at return period of 100 years with duration of 0.16 hours and minimum intensity of $1.69 \mathrm{~mm} / \mathrm{hr}$ at return period of 2 years with duration of 24 hours. The Pearson Type III distribution gives a maximum intensity of $81.13 \mathrm{~mm} / \mathrm{hr}$ at return period of 100 years with duration of 0.16 hours and minimum intensity of $1.86 \mathrm{~mm} / \mathrm{hr}$ at return period of 2 years with duration of 24 hours. The Log Pearson Type III distribution gives a maximum intensity of $93.67 \mathrm{~mm} / \mathrm{hr}$ at return period of 100 years with duration of 0.16 hours and minimum intensity of $2.04 \mathrm{~mm} / \mathrm{hr}$ at return period of 2 years with duration of 24 hours. The rainfall intensity values obtained using the three distributions are close for almost all return periods and rainfall durations.

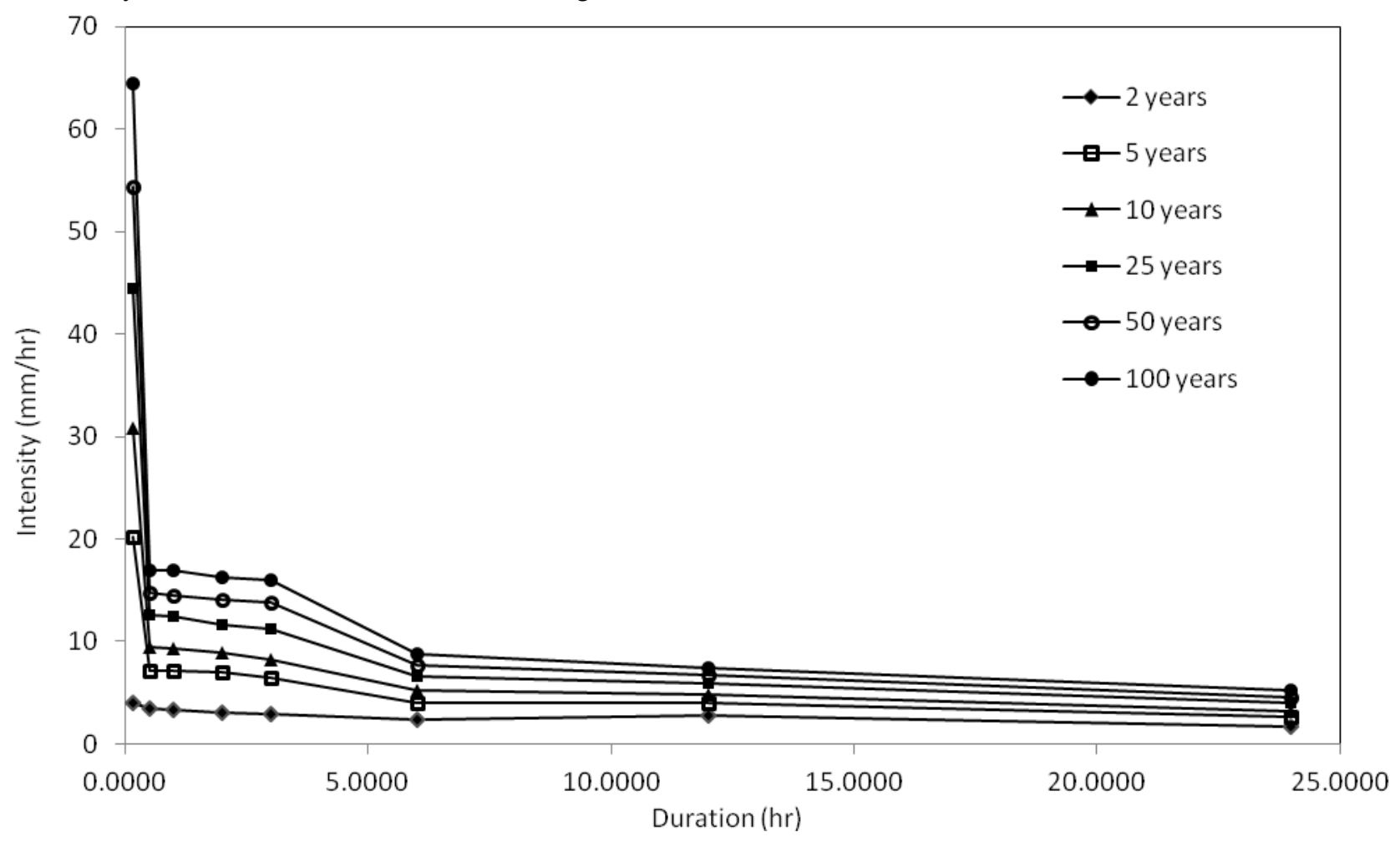

Figure 1. IDF curves by Gumbel distribution 


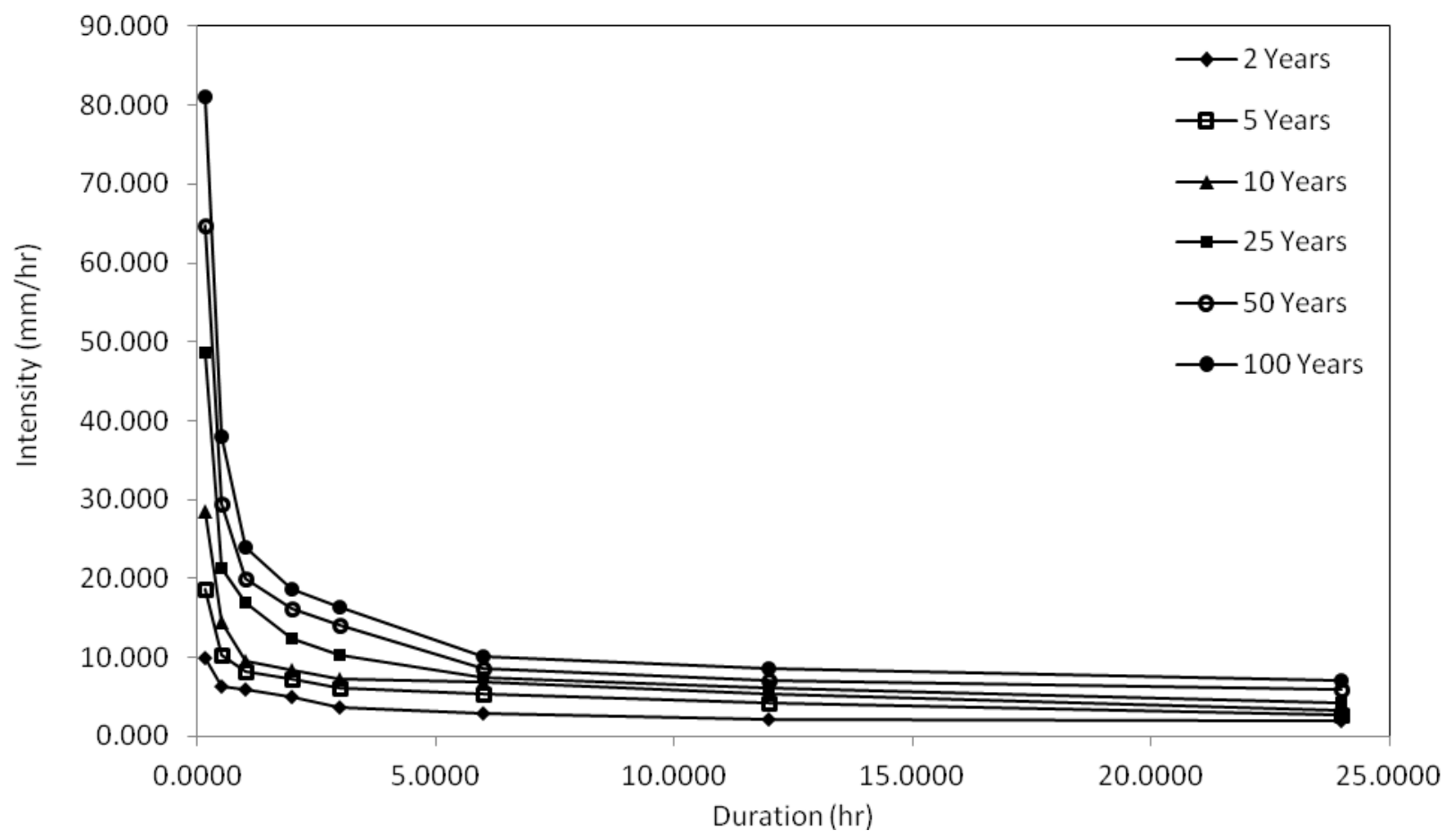

Figure 2. IDF curves by Pearson Type III distribution

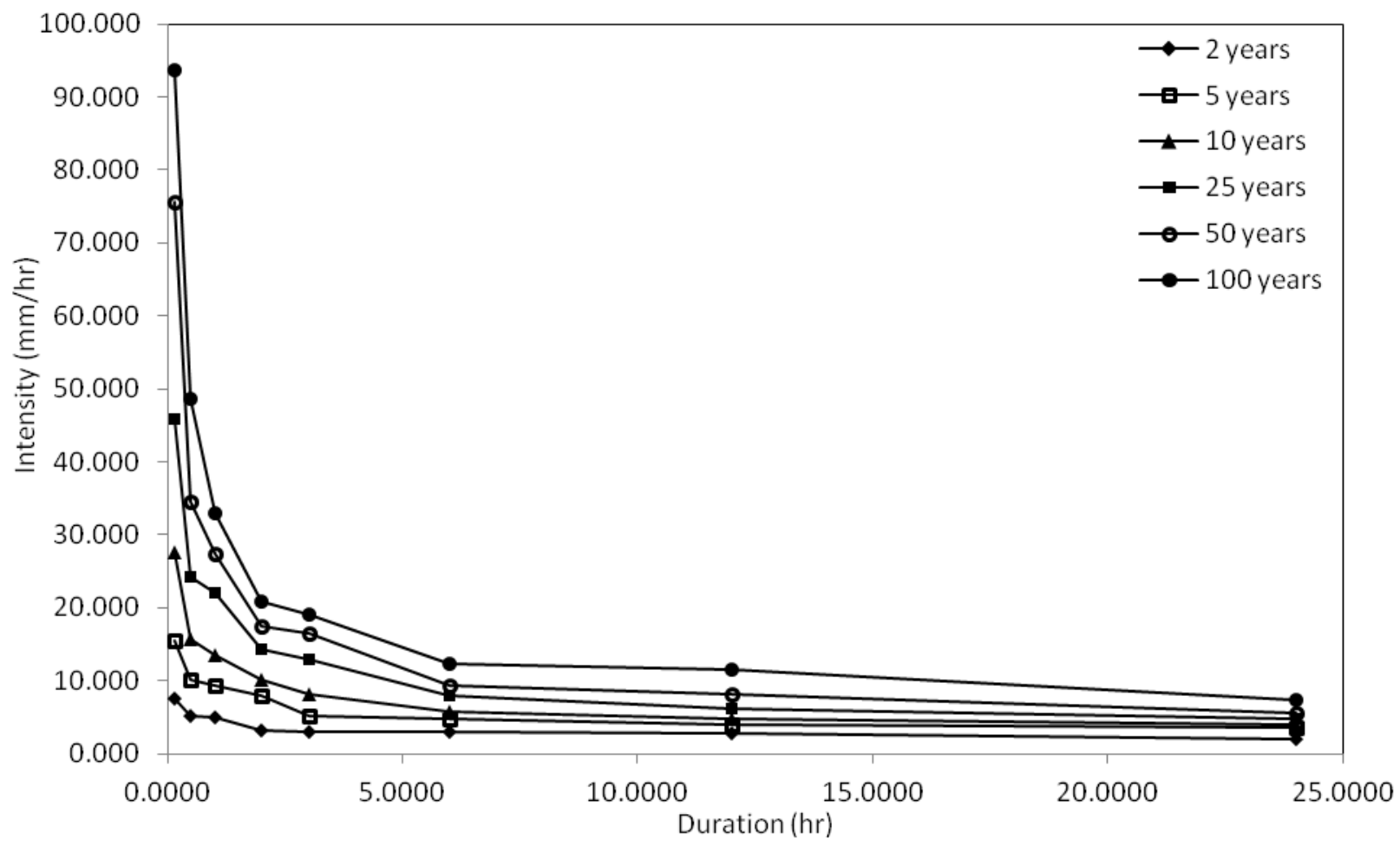

Figure 3. IDF curves by Log Pearson Type III distribution

It is seen that the IDF curves obtained from all of the three distributions show a similar trend. From the IDF curves, it can be inferred that the higher intensity rainfalls occur for only short durations and higher rainfall intensities also have longer return periods, that is, they are less frequent than the low intensity rainfalls. 


\subsection{IDF equations}

The IDF equation is linear in the logarithmic transform, and hence logarithm of intensity varies linearly with the logarithm of rainfall duration.

Equation (6) gives the IDF equation developed for Kupwara region using the Gumbel distribution.

$$
I=\frac{4.93 T^{0.189}}{T_{d}^{0.121}}
$$

Figure 4 shows a log-log plot of the above equation for different return periods and the curve fitting of rainfall intensity data obtained using the Gumbel distribution.

Equation (7) gives the IDF equation developed for Kupwara region using the Pearson Type III distribution.

$$
I=\frac{8.41 T^{0.171}}{T_{d}^{0.101}}
$$

Figure 5 shows a log-log plot of the above equation for different and the curve fitting of rainfall intensity data obtained using the Pearson Type III distribution for different return periods.

Equation (8) gives the IDF equation developed for Kupwara region using the Pearson Type III distribution.

$$
I=\frac{5.73 T^{0.220}}{T_{d}^{0.118}}
$$

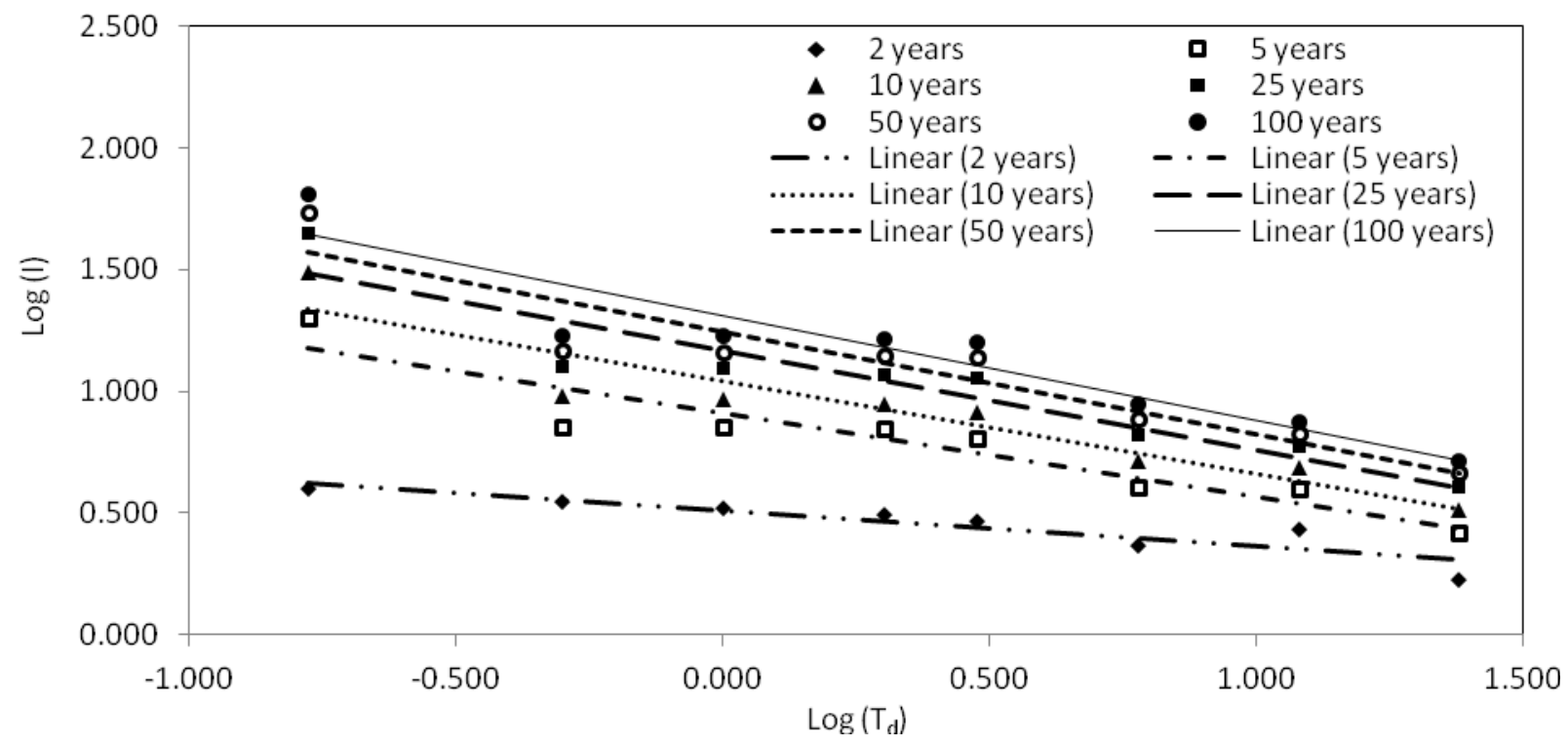

Figure 4. IDF equation generated using Gumbel distribution

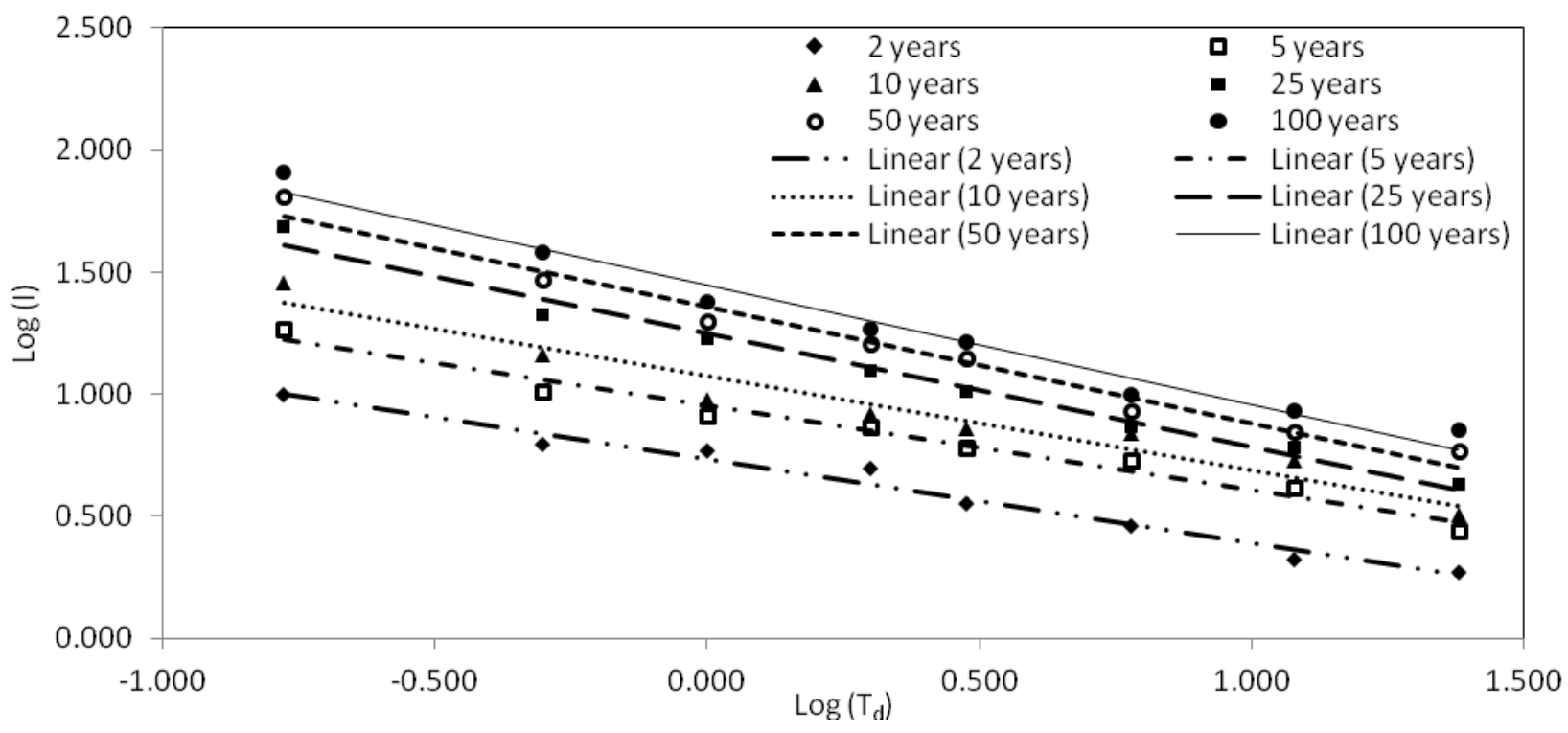

Figure 5. IDF equation generated using Pearson Type III distribution 


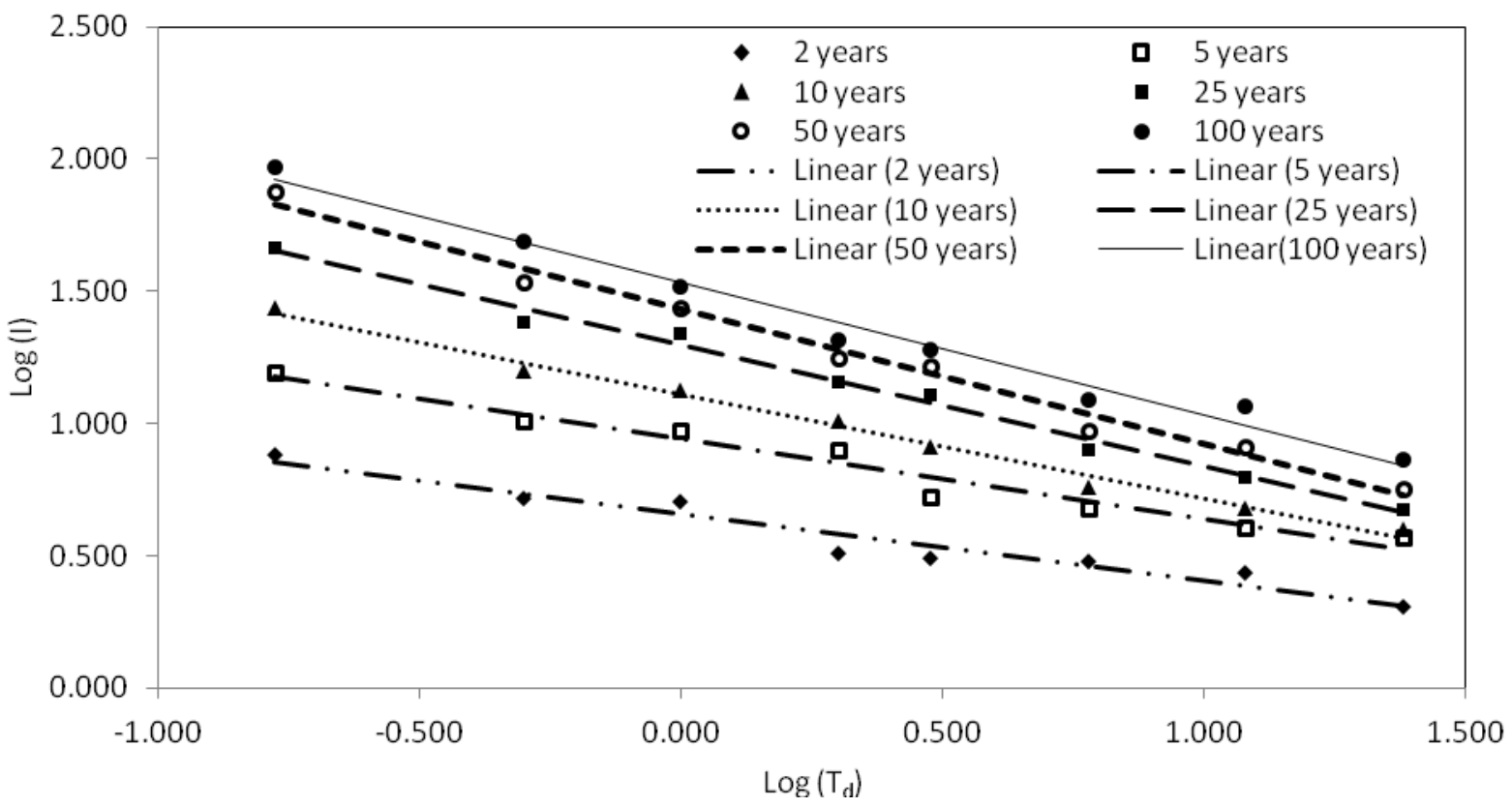

Figure 6. IDF equation generated using Log Pearson Type III distribution

Table 2. Values of chi-square statistic

\begin{tabular}{|c|c|c|c|c|c|c|c|c|}
\hline \multirow{2}{*}{ Distribution } & \multicolumn{9}{|c|}{ Duration (Hrs) } \\
\cline { 2 - 10 } & $\mathbf{0 . 1 6}$ & $\mathbf{0 . 5}$ & $\mathbf{1}$ & $\mathbf{2}$ & $\mathbf{3}$ & $\mathbf{6}$ & $\mathbf{1 2}$ & $\mathbf{2 4}$ \\
\hline Gumbel & 28.17 & 26.62 & 27.33 & 25.38 & 16.06 & 19.39 & 20.21 & 19.40 \\
\hline Pearson Type-III & 18.52 & 39.87 & 15.14 & 28.13 & 12.97 & 15.02 & 14.97 & 19.95 \\
\hline Log-Pearson Type-III & 20.75 & 22.29 & 28.53 & 19.85 & 30.23 & 20.42 & 20.92 & 27.55 \\
\hline
\end{tabular}

Figure 6 shows the curve fitting of rainfall intensity data obtained using the Log Pearson Type III distribution for different return periods.

Table 1 gives the values of regional constants in IDF equations obtained for the data generated using three different frequency distributions.

Table 1.Estimates for regional constants in IDF equations

\begin{tabular}{|c|c|c|c|}
\hline Parameters & Gumbel & $\begin{array}{c}\text { Pearson Type } \\
\text { III }\end{array}$ & $\begin{array}{c}\text { Log-Pearson } \\
\text { Type III }\end{array}$ \\
\hline $\mathrm{C}$ & 4.93 & 8.41 & 5.73 \\
\hline $\mathrm{m}$ & 0.189 & 0.171 & 0.220 \\
\hline $\mathrm{e}$ & 0.121 & 0.101 & 0.118 \\
\hline
\end{tabular}

\subsection{Chi-square goodness-of-fit test}

The Chi-square values for rainfall intensities with different durations and different return periods are given in Table 2.

\section{Conclusion}

An empirical technique has been applied to rainfall data in order to determine the Intensity-Duration-Frequency characteristics of rainfall and the underlying distribution.
Three different frequency distributions namely the Gumbel distribution, the Pearson Type III distribution and the LogPearson Type III distribution have been fitted to the rainfall data to obtain rainfall intensities for selected return periods $(2,5,10,25,50$ and 100 years $)$ and durations $(0.16,0.5,1$, $3,6,12$ and 24 hours). In general, the results obtained using the three approaches are very close at most of the return periods and have the same trend. For Kupwara region, as per the best fit distribution, maximum intensity for of $81.13 \mathrm{~mm} / \mathrm{hr}$ occurs at return period 100 years with duration of 0.16 hours and minimum intensity of 1.86 occurs at return period 2 years with duration of 24 hours. As per the Chi-square goodness-of-fit test, the Pearson Type III distribution gives the best fit for the rainfall pattern in Kupwara region.

\section{References}

1. F. C. Bell. "Generalized rainfall-duration-frequency relationships." Jr. Hydraul. Div., 95(1), 311-327, (1969).

2. A. A. Al-Shaikh. "Rainfall frequency studies for Saudi Arabia." M.S. Thesis. Civil Engineering Department, King Saud University, Riyadh (K.S.A), (1985). 
3. H. A. Al-Khalaf. "Predicting short-duration, highintensity rainfall in Saudi Arabia." M.S. Thesis, Faculty of the College of Graduate Studies; King Fahad University of Petroleum and Minerals, Dahran (K.S.A), (1997).

4. D. Koutsoyiannis, D. Kozonis and A. Manetas. "A mathematical framework for studying rainfall intensity- duration-frequency relationships." Jr. Hydrol., 206, 118-135, (1998).

5. I.H. Elsebaie, "Developing rainfall intensity-durationfrequency relationship for two regions in Saudi Arabia." Jr. King Saud Univ.-Engg. Sci., 24, 131-140, (2012).

6. N. M. Ogarekpe. "Development and comparison of different intensity duration frequency models for calabar, nigeria."Nigerian Jr. Tech. 33(1), 33-42, (2014).

7. A. A. Al-Dokhayel. "Regional rainfall frequency analysis for Qasim.” B. S. Project, Civil Engineering Department, King Saud University, Riaydh (K.S.A), (1986).

8. B. S. Dupont and D. L. Allen, D.L. "Revision of the Rainfall Intensity Duration Curves for the
Commonwealth of Kentucky. Kentucky Transportation Center, College of Engineering, University of Kentucky, USA. (2000).

9. N. A. Hadadin. "Rainfall intensity-duration-frequency relationship in the Mujib basin in Jordan." Jr. App. Sci., 8 (10), 1777-1784, (2005).

10. L. M. Nhat, Y. Tachikawa and K. Takar. "Establishment of intensity-duration-frequency curves for precipitation in the monsoon area of Vietnam." Annuals of Disas. Prev. Res. Inst., Kyoto University, No. 49 B, (2006).

11. S. A. AlHassoun. "Developing an empirical formulae to estimate rainfall intensity in Riyadh region." $J r$. King Saud Univ. Engg. Sci., 23(2), 81-8, (2011).

12. V. T. Chow. Handbook of Applied Hydrology, McGraw-Hill Book, (1988).

13. C. B. Burke and T.T. Burke. Storm Drainage Manual. Indiana LTAP. (2008).

14. Water Resources Council, Bulletin No. 15, Water Resources Council, 1025 Vermont Avenue, N. W. Washington, D. C., 200005, (1967). 